\title{
Dynamics of progesterone and estrogen receptor alpha in the ventromedial hypothalamus
}

\author{
Susana I Sá1,2 and Bruno M Fonseca ${ }^{3}$ \\ 1Department of Biomedicine, Unit of Anatomy, Faculty of Medicine, University of Porto, Porto, Portugal \\ 2Faculty of Medicine, Center for Health Technology and Services Research (CINTESIS), University of Porto, \\ Porto, Portugal \\ 3UCIBIO, REQUIMTE, Department of Biological Sciences, Laboratory of Biochemistry, Faculty of Pharmacy, \\ University of Porto, Porto, Portugal
}

Correspondence should be addressed to S I Sá

Email sasusana@med.up.pt

\begin{abstract}
Cyclic fluctuations of estradiol and progesterone in females influence neuronal activity in the ventrolateral division of the ventromedial hypothalamic nucleus (VMNvl), through the activation of progesterone receptors (PRs) and estrogen receptors (ERs). The expression of ER and PR in the VMNvl is influenced by their cognate ligands and is a central upstream trigger in the pathway of VMNvI-dependent modulation of endocrine responses. By studying the role played by estradiol and progesterone in PR and ERa expression in the VMNvl along the estrous cycle and how the two receptors interact in the same neuron, we aim to evaluate the synergistic action of both ovarian hormones in the regulation of VMNvl activity. In animals at all phases of the estrous cycle, the number of VMN neurons expressing PR or ERa was estimated by stereological methods, and the percentage, and rostro-caudal distribution, of neurons simultaneously expressing both receptors was determined. The highest number of PR-immunoreactive neurons was seen at proestrus, and of ERa-immunoreactive neurons was seen at proestrus and metestrus. The ERa/PR co-localization is increased at caudal levels. Approximately half the neurons expressing PR co-express ERa, a proportion that stays constant along the estrous cycle. The percentage of ERa neurons co-expressing PR changes from $60 \%$ at proestrus to $40 \%$ at metestrus. Fluctuations in circulating ovarian hormone levels promote coordinated changes in PR and ERa expression and co-localization. This may be an important mechanism in the regulation of input relayed by the $\mathrm{VMNvl}$, allowing a precise modulation of endocrine responses.
\end{abstract}

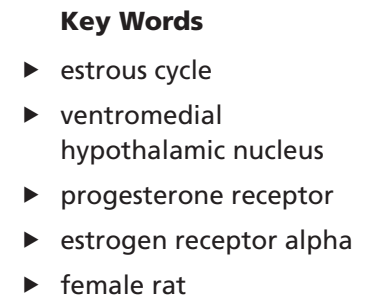

Journal of Endocrinology (2017) 233, 197-207

\section{Introduction}

In the female brain, cyclic fluctuations of the ovarian steroids estradiol and progesterone exert a profound influence on neuronal circuits involved in the regulation of goal-oriented behaviors fundamental to the species survival, such as food intake and sexual behavior (Pfaff et al. 2008, Blaustein 2009, Liu \& Shi 2015). One hypothalamic nucleus that plays a preponderant role in these behavioral answers is the ventromedial nucleus of the hypothalamus (VMN), a group of cells particularly targeted for steroid hormone action and specifically involved in the estradiol- and progesterone-dependent regulation of neuroendocrine function (Etgen et al. 1999, 
Pfaff et al. 2008, Yang et al. 2013). The ventrolateral division of the VMN (VMNvl) expresses estrogen receptor (ER) a and $\mathrm{b}$ and progesterone receptors (PRs), which depend on the levels of their cognate ligands (Lauber et al. 1990, Shughrue et al. 1992, Sá et al. 2013, 2015). Earlier studies have demonstrated that ERa expression in the VMNvl is increased on ovariectomy and at proestrus, the stage of the estrous cycle when estradiol and progesterone levels are the highest (McGinnis et al. 1981, Lauber et al. 1990, Shughrue et al. 1992, Guerra-Araiza et al. 2003). Studies that specifically activated or inhibited ERs have shown that the activation of ERa or of ERa and ERb induces the expression of estradiol-inducible and non-inducible PRs (Moffat et al. 1998, Kudwa \& Rissman 2003, Sá et al. 2013), whose activation is paramount to the complete execution of the female sexual behavior (Micevych et al. 2008, Mani \& Oyola 2012, Snoeren et al. 2015). The role of progesterone in the modulation of sexual behavior is enhanced by its ability to promote post-estrous refractoriness, ending the estrous behavior and inducing a sort of reset of the neuronal circuitry involved in the regulation of female sexual behavior (Parsons et al. 1981, Mani \& Oyola 2012).

In a previous study, it was shown that the structural and biochemical plasticity induced by estradiol in the VMNvl are differently regulated by its connections, in a way that synaptic plasticity is dependent on VMN external connections, whereas the expression of PRs was not (Sá et al. 2010). Calizo and coworkers (Calizo \& Flanagan-Cato 2002, 2003) proposed that the VMNvl is formed by four different neuronal populations, according to its ERa expression and projection to the periaqueductal gray. However, these studies failed to perceive any correlation between neuronal phenotype and the degree of activation upon sexual sensory stimulation, suggesting that even interneurons that do not express ERa are able to regulate female sexual behavior and estrous termination. Furthermore, a previous study has shown the importance of this neuronal population in the promotion of the female sexual behavior by ablating the VMNvl neurons that express PR (Yang et al. 2013). Evidences reported by these previous studies suggest the existence of an intrinsic regulation of PRs by estradiol through ERa in the VMNvl, which is able to respond dynamically to different stimuli to regulate female sexual behavior. To our knowledge, only a few studies have addressed the existence of neurons co-expressing ERa and PR, showing an almost complete co-localization of PR and ERa in the ventromedial hypothalamus region (Blaustein \& Turcotte 1989, Warembourg et al. 1989). However, those studies were done in guinea pig, and the effects of estradiol and progesterone levels in normally cycling rats were not evaluated.

Therefore, it is hypothesized that the coordinated modulation of PR and ERa expression by cycling levels of estradiol and progesterone could change the number of neurons co-expressing both receptors exerting, in this way, a strict modulation of the pathways leading to the induction and termination of the estrous behavior. In this study, stereological methods were used to estimate the total number of VMNvl neurons that express PR and ERa along the four phases of the estrous cycle and the influence of the cycling ovarian hormones on the simultaneous expression of both receptors in the same neuron. As VMN connections are topographically organized (Sakuma \& Akaishi 1987, Fahrbach et al. 1989, Flanagan-Cato 2000) and neurons that express PR and ERa are differently distributed along the rostro-caudal extent of the VMNvl, the aim of this study was also to determine the changes in the fraction of neurons that co-express PR and ERa along the rostro-caudal levels of the VMNvl.

\section{Materials and methods}

\section{Animals and treatments}

Female Wistar rats from the Institute for Molecular and Cell Biology (Porto, Portugal) were maintained under standard conditions with a 12-h light:12-h darkness cycle (07:00-19:00 h) and ambient temperature of $23^{\circ} \mathrm{C}$. Food and water were available ad libitum. Estrous cycles were monitored daily by vaginal smear cytology starting at the age of 8 weeks, and only animals exhibiting consecutive 4to 5-day estrous cycles were used. At the age of 12 weeks, rats at all stages of the estrous cycle ( $n=5$ per stage) were anesthetized with $2 \mathrm{~mL} / \mathrm{kg}$ b.w. of a solution containing sodium pentobarbital $(10 \mathrm{mg} / \mathrm{mL})$ given intraperitoneally and killed by intracardiac perfusion of a fixative solution containing $4 \%$ paraformaldehyde in $0.1 \mathrm{M}$ phosphate buffer, $\mathrm{pH}$ 7.6. All animal experimentation was conducted in agreement with accepted standards of animal care and in accordance with the European Communities Council Directives of 22 September 2010 (2010/63/EU) and Portuguese Act $n^{\circ} 113 / 13$.

\section{Hormonal determinations}

Prior to perfusion, blood samples $(2000 \mu \mathrm{L})$ were taken directly from the heart into the Eppendorf tubes. 
After complete clot formation, each sample was centrifuged twice at $1100 \boldsymbol{g}$ for $10 \mathrm{~min}$. Serum was then removed, collected in aliquots and stored undiluted at $-80^{\circ} \mathrm{C}$ until further analysis. Estradiol and progesterone serum levels were assayed by enzyme-linked fluorescent assay using VIDAS Progesterone and Estradiol II Kits and mini VIDAS analyzer (bioMerieux S.A., Marcy L'Etoile, France). According to the manufacturer, the assay has a measurement range of $9-3000 \mathrm{pg} / \mathrm{mL}$ and $0.25-80 \mathrm{ng} / \mathrm{mL}$ for estradiol and progesterone, respectively. The analyzer was cleaned, calibrated and operated in accordance with the manufacturer's instructions. All samples were tested in singlicate.

\section{Tissue preparation and immunohistochemistry}

Upon killing, the brains were removed from the skulls, post-fixed for $1 \mathrm{~h}$ in the same fixative solution at $4^{\circ} \mathrm{C}$, and then transferred to a solution of $10 \%$ sucrose in phosphate buffer at $4^{\circ} \mathrm{C}$, where they were maintained overnight. Brains were transected in the coronal plane through the anterior border of the optic chiasm, rostrally, and the posterior limit of the mammillary bodies, caudally. These blocks of tissue were mounted on a Vibratome with the rostral surface up and sectioned at $40 \mu \mathrm{m}$ throughout the rostro-caudal extent of the VMN. Each set of sections used for PR or ERa immunocytochemical detection with diaminobenzidine were sampled at regular intervals of $120 \mu \mathrm{m}$ (1 out of 3 ), and each set of sections used for the fluorescent detection of PR and ERa immunoreactivity were sampled at regular intervals of $240 \mu \mathrm{m}$ ( 1 out of 6 ).

Sections collected for the estimation of the total number of PR-immunoreactive (PR-ir) or ERaimmunoreactive (ERa-ir) neurons were processed as previously described (Sá et al. 2013, 2015, Leite et al. 2014, Martins et al. 2015). Briefly, sections were treated with $3 \% \mathrm{H}_{2} \mathrm{O}_{2}$, washed with phosphate buffered saline (PBS) and then blocked with 5\% normal serum. The antiserum against PR (MAB462, Millipore) was used at a dilution of 1:2000, and the antiserum against ERa (MC20, Santa Cruz Biotechnology) was used at a dilution of 1:1000. Each set of sections were incubated in the respective primary antibody for $72 \mathrm{~h}$, at $4^{\circ} \mathrm{C}$ and then in the corresponding secondary antibody, the biotinylated horse IgG antimouse antibody and the biotinylated goat IgG anti-rabbit antibody, respectively (Vector Laboratories, Peterborough, $\mathrm{UK})$, at a 1:400 dilution for $1 \mathrm{~h}$ at room temperature. Afterward, sections were treated with avidin-biotin peroxidase complex (Vectastain Elite ABC Kit; Vector
Laboratories), at a 1:800 dilution, for $1 \mathrm{~h}$ at room temperature, followed by incubation, for $85 \mathrm{~s}$, in $0.05 \%$ diaminobenzidine (Sigma-Aldrich) to which $0.01 \% \mathrm{H}_{2} \mathrm{O}_{2}$ was added. Between each step, sections were rinsed with PBS. Stained sections were mounted on gelatin-coated slides, dehydrated and coverslipped using Histomount (National Diagnostics, Atlanta, GA, USA).

Sections collected for immunofluorescence were blocked for $1 \mathrm{~h}$ in a solution of 5\% normal serum, and then incubated for $72 \mathrm{~h}$ at $4^{\circ} \mathrm{C}$ in a solution containing both primary antibodies at the stated dilutions. Then, sections were incubated, in the dark, in a solution containing both secondary antibodies, Alexa Fluor 568 goat antimouse and 488 goat anti-rabbit (A-11031 and A-11008; Life Technologies Europe BV), at a $0.5 \%$ dilution for $2 \mathrm{~h}$ at room temperature. Between each step, sections were rinsed with PBS. After that, sections were coverslipped with FluorSave to which 4',6-diamidino-2-phenylindole, dihydrochloride (DAPI, D1306, Life Technologies Europe BV), was added at a 1:100 dilution.

Sets of sections of animals of all groups were processed together for either immunohistochemistry procedure to avoid variation across groups.

\section{Antibody characterization}

The ERa antibody used is a polyclonal rabbit antibody from Santa Cruz Biotechnology (MC-20, sc-542, RRID:AB_631470) prepared against a peptide mapping the amino acids 580HSLQTYYIPPEAEGFPNTI599, at the C-terminus of mouse ERa. The specificity of this antibody has been confirmed by the disappearance of signal after preabsorption with the epitope peptide and adult uterine cytosol (Omoto et al. 2005, Quesada et al. 2007, Fig. 1). In a spot blot test, the MC-20 recognized its blocking peptide on nitrocellulose paper, and after adsorption of the primary antibody to its blocking peptide, no staining was observed (Fernández-Guasti et al. 2000). In previous studies, we and other researchers have shown differences in distribution of the ERa using the same antibody in rat hypothalamus and preoptic area and one specific $68-\mathrm{kDa}$ band in a western blot of rat hypothalamus (Kruijver et al. 2002, Normandin \& Murphy 2008, Garcia-Falgueras et al. 2011, Malikov \& Madeira 2012, Leite et al. 2014, Martins et al. 2015, Rebouças et al. 2016).

The antibody used for PR labeling, the mouse monoclonal antiserum a.a. 922-933, clone 6A, prepared against a peptide mapping the amino acids 922AGMVKPLLFHKK933 (MAB462, RRID:AB_2164323, 

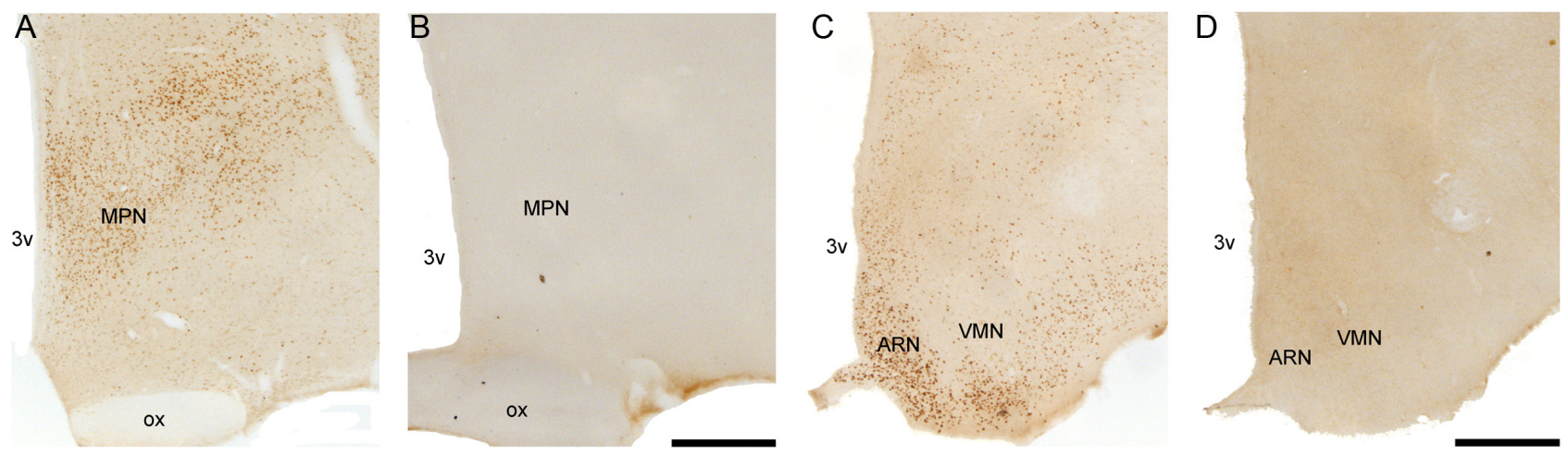

Figure 1

Representative photomicrographs of adjacent coronal sections through the medial preoptic nucleus (A, B) and the VMN (C, D) showing the peptideinhibition experiment of the ERa antibody MC-20 with the corresponding blocking peptide (sc-542 P). A normal IHC procedure using the MC-20 antibody at 1/1000 showing immunostained neurons in the medial preoptic nucleus (A) and in the VMN and arcuate nucleus (C). No immunostaining signal is seen when the antibody is incubated with the peptide $10 \times$ concentrated $(B, D)$. Scale bar $=150 \mu \mathrm{m}$. 3v, third ventricle; ARC, arcuate nucleus; MPN, medial preoptic nucleus; ox, optic chiasm; VMN, hypothalamic ventromedial nucleus.

Chemicon, Millipore Iberica), recognizes both the A and B isoforms of the human progestin receptor. The specificity of this antibody has been demonstrated by preadsorption with the immunizing peptide (Tetel et al. 2007). This antibody recognizes PRA and PRB bands on western blots of estrogen-treated hypothalamic cell lines and rat uteri (Fitzpatrick et al. 1999) of T47D-Y breast cancer cells and human uterine myosarcoma cell line SKUT-1B (Samalecos \& Gellersen 2008, Lee et al. 2010). In our laboratory, the distribution of PR-positive neurons in the VMN (Sá et al. 2010, 2013, 2014) matched previous observations made by other researchers using the same antibody (Blaustein \& Gréco 2002, Tetel et al. 2007).

\section{Estimation of the total number of PR- and ERa- immunoreactive neurons}

The optical fractionator method (West et al. 1991, Madeira et al. 1997) was applied to estimate the total number of PR- or ERa-ir neurons in the VMNvl. Sections were analyzed using a modified Olympus $\mathrm{BH}-2$ microscope interfaced with a color video camera and equipped with a Heidenhain ND 281 microcator (Traunreut, Germany), a computerized stage, and an object rotator (Olympus). A computer fitted with a frame grabber (Screen Machine II, FAST Multimedia, Germany) was connected to the monitor. By using the C.A.S.T. - Grid system software (Olympus), the fields of view of both receptors were systematically sampled at regular intervals of $100 \mu \mathrm{m}$ along the $x$ and $y$ axes. The counting frame area of both dissectors was $1486 \mu \mathrm{m}^{2}$ at the tissue level with a fixed depth of $10 \mu \mathrm{m}$. The estimations were performed with a 100x oil immersion lens with a numerical aperture of 1.40 , which produced a final magnification of $2000 \times$ in the computer screen. Cell profiles were considered immunopositive for PR or ERa whenever a dark brown reaction product was present within the cell nucleus of either immunolabeling (Fig. 2). On an average, 200 PRand 200 ERa-ir cells were counted per VMNvl; the mean coefficient of error (Gundersen et al. 1999) of the estimates was 0.07 for PR and 0.06 for ERa. All counts were made by an observer who was blinded to group assignment.

\section{Fluorescence quantification}

Fluorescence image acquisition was made using a Leica DC 300F color video camera (Leica Microsystems Imaging Solutions) connected to a Leica DMR light microscope (Leica Microsystems Imaging Wetzlan $\mathrm{GmbH}$ ), using a 63×/1.32-0.6 objective lens (HCX PL APO). The double-labeled neurons were detected by observing the cells through an N2.1 filter (excitation wavelength $515-560 \mathrm{~nm}$ ) for PR immunoreactivity detection and a L5 filter (excitation wavelength $480 / 40 \mathrm{~nm}$ ) for ERaimmunoreactivity detection (Fig. 3). DAPI was detected using an A filter (excitation wave length 340-380 nm). For each rat, three sections, level match, containing the VMNvl were sampled, at the rostro-caudal levels approximately Bregma $-2.3 ;-2.8 ;-3.3$ (Paxinos \& Watson 1998). Images of either immunolabeling were captured in a optic plan in one region of interest with an area of $57,766.42 \mu \mathrm{m}^{2}$ in each of the three VMNvl sections (with a total area of $173,299.26 \mu \mathrm{m}^{2}$ per rat), by switching from one filter cube to the other, using the 

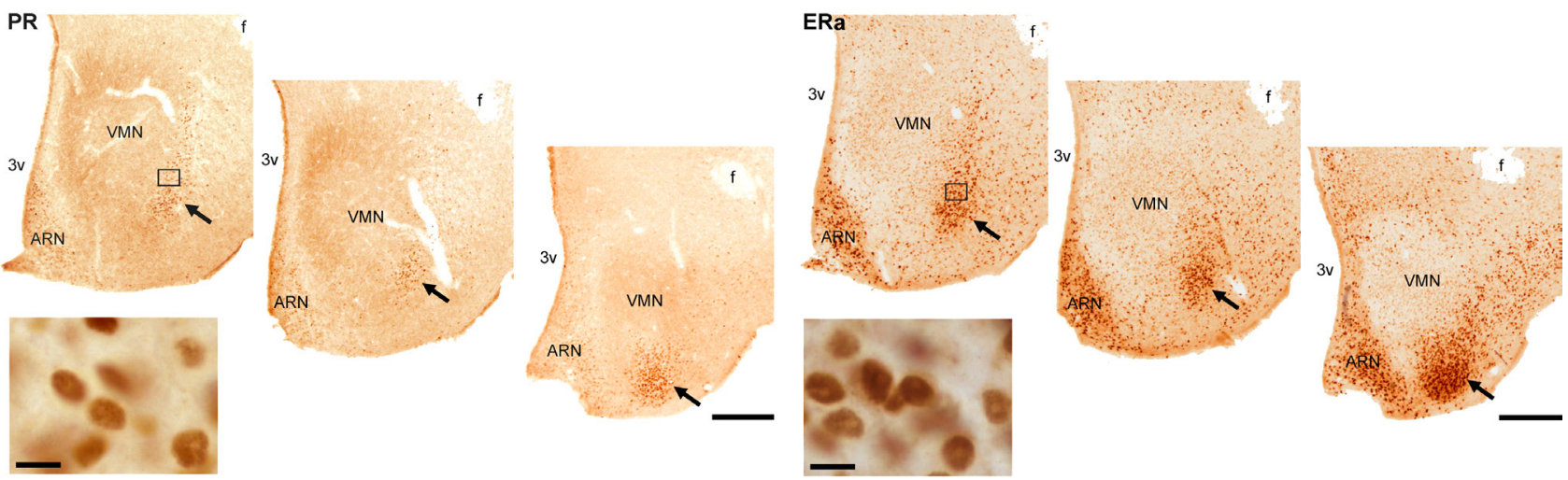

Figure 2

Representative photomicrographs of adjacent coronal sections through the rostro-caudal extent of the VMN, arranged from rostral to caudal levels, showing the VMNvl (arrow) immunostained for PR or ERa (Bregma level approximately $-2.30,-2.80$ and $-3.30 \mathrm{~mm}$ ). Scale bar $=150 \mu \mathrm{m}$. Inset: higher magnification of the area delineated by a box in the upper image, showing PR-ir or ERa-ir neurons with a dark brown immunostained nucleus and a relatively unstained cytoplasm. Scale bar $=5 \mu \mathrm{m}$. 3v, third ventricle; ARC, arcuate nucleus; f, fornix; VMN, hypothalamic ventromedial nucleus.

same image settings for each filter cube. Cell counts were performed using ImageJ software after superimposition of the two images of the same region of interest. An average of 135 PR-ir and 135 ER-ir neurons were counted per VMNvl. Quantitative data were expressed as percentage of co-localization, i.e., percentage of PR- or ERa-ir cells that also express the other receptor. As diaminobenzidine immunohistochemistry revealed different rostro-caudal distribution of PR- and ERa-ir neurons, the percentage of PR/ERa and ERa/PR co-localization at rostral (Bregma level approximately -2.16 to -2.28 ), medial (Bregma level approximately -2.64 to -2.76 ) and caudal levels (Bregma level approximately -3.12 to -3.24 ) (Paxinos \& Watson 1998), was also calculated. An average of six regions of interest was analyzed per rat.

\section{Statistical analyses}

The influence of ovarian hormone changes along the estrous cycle on uterine weight, hormonal levels and
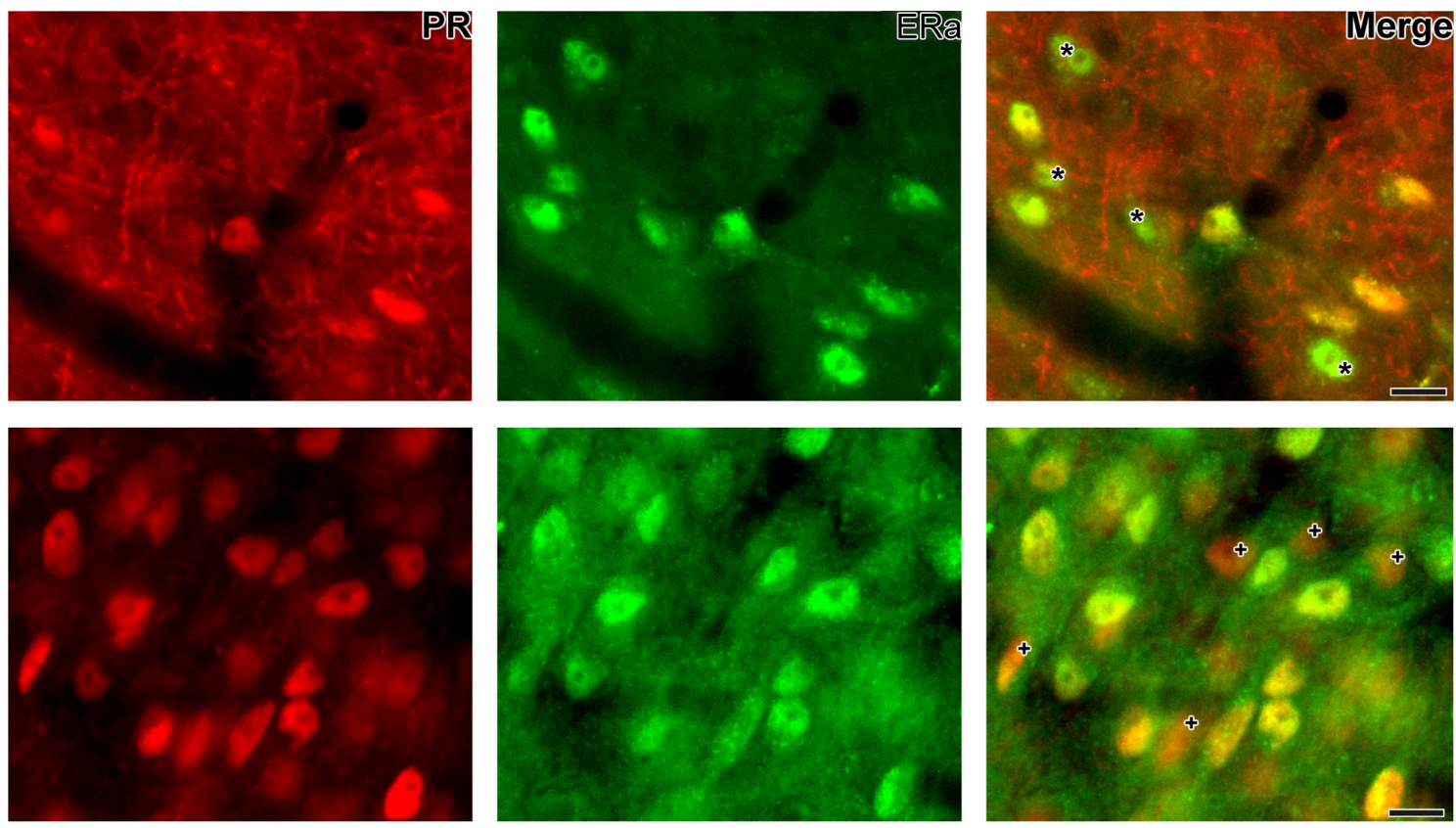

Figure 3

Fluorescence microscopy images of VMNvl neurons stained with Alexa Fluor 568 (red, PR-ir), with Alexa Fluor 488 (green, ERa-ir) or with both (yellow, co-localization). The upper set shows ERa-ir neurons that do not express PR (asterisk) and the lower set shows PR-ir neurons that do not express ERa (cross). Scale bar $=10 \mu \mathrm{m}$. 
Table 1 Uterine weights and hormonal determinations.

\begin{tabular}{|c|c|c|c|c|}
\hline & Diestrus & Proestrus & Estrus & Metestrus \\
\hline Uterine weight (g) & $0.47(0.03)$ & $0.84(0.06) *$ & $0.47(0.02)$ & $0.44(0.04)$ \\
\hline Estradiol levels (pmol/L) & $79.83(10.03)^{++}$ & $270.72(9.67)$ & $37.86(2.24)^{++, \phi}$ & $49.70(7.36)^{++}$ \\
\hline Progesterone levels (nmol/L) & $30.07(1.38)^{++, \#}$ & $126.53(4.61)$ & $24.11(1.91)^{++, \#}$ & $93.45(8.94)^{+}$ \\
\hline
\end{tabular}

receptor expression in the $\mathrm{VMNvl}$ was assessed by one-way analysis of variance (ANOVA). The influence of the estrous cycle in the rostro-caudal distribution of the receptor co-localization was assessed by two-way ANOVA. Pairwise comparisons were made using the post hoc Tukey's HSD test (GraphPad Prism, version 6.0; GraphPad Software). Differences were considered significant if $P<0.05$.

\section{Results}

\section{Uterine weight and hormonal determinations}

As expected, a significant overall difference was observed on uterine weights $(F(3,16)=20.97, P<0.0005)$ as well as in estradiol $(F(3,16)=187.3, P<0.0005)$ and progesterone $(F(3,16)=92.91, \quad P<0.0005)$ levels. Uteri of rats were 2-times heavier at proestrus than at any other stage of the cycle. There were no differences in the uterine weight of rats at diestrus, estrus or metestrus (Table 1). Estradiol levels were 3-, 7- and 5-times higher at proestrus when compared with diestrus, estrus and metestrus phases, respectively, and 2-times higher at diestrus than at estrus phase (Table 1). Progesterone levels were 4-, 5- and 1.4times higher at proestrus than at diestrus, estrus and metestrus phases, respectively, and 3- and 4-times higher
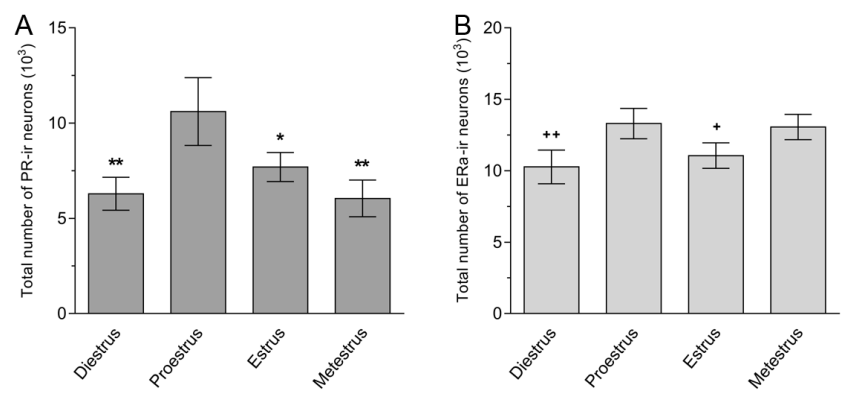

Figure 4

Graphical representation of the total number of PR-ir (A) and ERa-ir (B) neurons in the VMNvl of rats at four phases of the estrous cycle (diestrus, proestrus, estrus and metestrus). Columns represent means \pm s.D. Tukey HSD test: ${ }^{*} P<0.001,{ }^{*} P<0.01$, compared with proestrus groups; ${ }^{++} P<0.001,+P<0.05$, compared with proestrus and estrus groups. at metestrus when compared with diestrus and estrus phases, respectively (Table 1 ).

\section{Effect of the estrous cycle on the total number of PR- and ERa-immunoreactive neurons}

ANOVA revealed significant variations induced by the stage of the estrous cycle in the total number of PR- $(F(3,16)=16.19, \quad P<0.0005)$ and ERa-ir neurons $(F(3,16)=10.91, P<0.0005)$ in the VMNvl. The total number of PR-ir neurons increased nearly 70\% from diestrus to proestrus and decreased nearly 30\% from proestrus to estrus phase (Fig. 4A). The total number of ERa-ir neurons increased nearly 30\% from diestrus to proestrus phase and nearly $20 \%$ from estrus to metestrus phase. ERa-ir neuron numbers decreased nearly $15 \%$ from proestrus to estrus phase and nearly $25 \%$ from metestrus to diestrus phase (Fig. 4B).

\section{Percentage of PR and ERa co-localization in VMNvl neurons}

The phase of the estrous cycle significantly influenced the percentage of ERa-ir VMNvl neurons that co-express PR $(F(3,16)=17.03, P<0.005)$ but not the percentage of
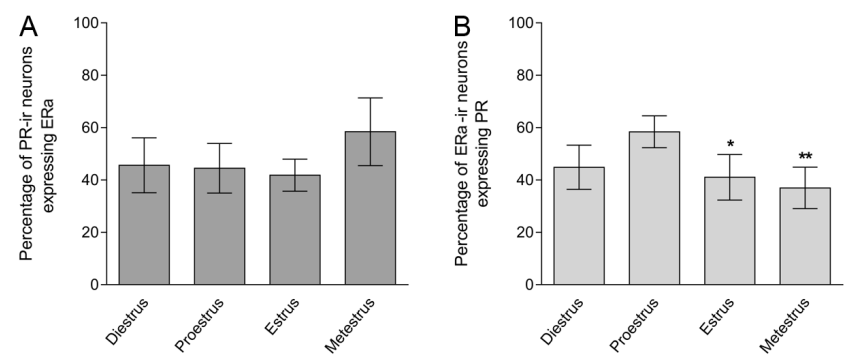

Figure 5

Graphical representation of the percentage of PR-ir neurons that co-express ERa (A) and of ERa-ir neurons that co-express PR (B) in the VMNvl of rats at the four phases of the estrous cycle (diestrus, proestrus, estrus and metestrus). Columns represent means \pm S.E.M. Tukey HSD test: ${ }^{*} P<0.01, * P<0.05$, compared with proestrus groups.

Published by Bioscientifica Ltd. 

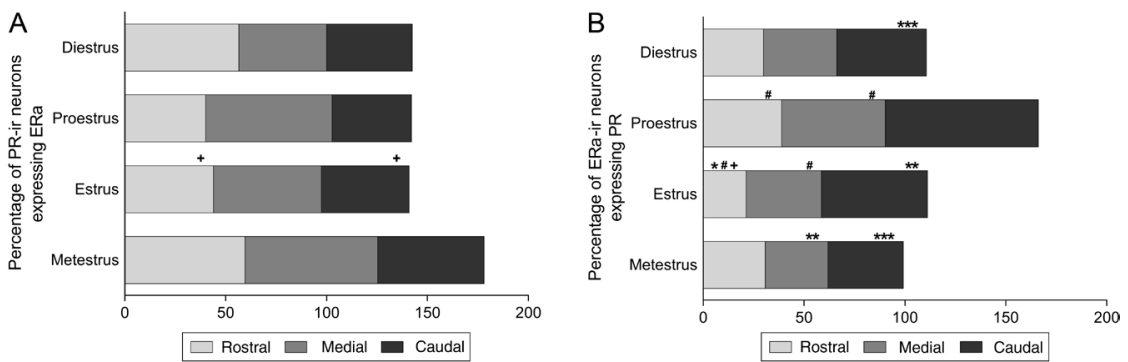

\section{Figure 6}

Graphical representation of the rostro-caudal distribution of the percentage of PR-ir neurons that co-express ERa (A) and of ERa-ir neurons that co-express PR (B) in the VMNvl of rats at four phases of the estrous cycle (diestrus, proestrus, estrus and metestrus). Columns represent means. Tukey HSD test: $* * * P<0.001, * * P<0.01, * P<0.05$, compared with proestrus groups in the same VMNvl level; ${ }^{+} P<0.05$, compared with VMNvl medial level at the same phase of the estrous cycle, $\# P<0.001$, compared with VMNvl caudal level at the same phase of the estrous cycle.
PR-ir VMNvl neurons that co-express ERa $(F(3,16)=2.71$, $P=0.080$; Fig. 5A). At estrus and metestrus phases, the percentage of ERa-ir neurons that express PR was 30 and $35 \%$ lower, respectively, than at proestrus phase (Fig. 5B).

\section{Percentage of PR and ERa co-localization along VMNvl rostro-caudal levels}

As revealed by the two-way ANOVA, the percentage of PR-ir neurons expressing ERa (Fig. 6A) was influenced by the estrous cycle $(F(3,48)=2.94, P<0.05)$ and by the rostro-caudal levels of the $\operatorname{VMNvl}(F(2,48)=3.79, P<0.05)$. No significant interaction between the estrous cycle and the rostro-caudal level was detected $(F(6,48)=1.52$, $P=0.19)$. In proestrus rats, the percentage of $P R$-ir neurons expressing ERa was 1.6 times higher at mid-levels than at rostral or caudal levels of the VMNvl. There were no changes in the percentage of PR-ir neurons expressing ERa along the rostro-caudal levels in diestrus, estrus and metestrus rats.

The two-way ANOVA revealed a significant effect of estrous cycle $(F(3,48)=16.79, P<0.0005)$ and the rostrocaudal levels of the $\operatorname{VMNvl}(F(2,48)=28.11, P<0.0005)$ on the percentage of ERa-ir neurons expressing PR (Fig. 6B). A significant interaction between the estrous cycle and the rostro-caudal levels was detected $(F(6,48)=2.98$, $P<0.05)$. At caudal levels, the percentage of ERa-ir neurons expressing PR was higher at proestrus than at any other phase of the estrous cycle. Specifically, it was approximately 1.4, 1.7 and 2 times higher when compared with estrus, diestrus and metestrus rats, respectively. At proestrus, the percentage of ERa-ir neurons expressing PR was 1.5 and 2 times higher in caudal levels than in the mid and the rostral levels, respectively.

\section{Discussion}

For the first time, data in this study show that ERa/PR co-localization changes along the rostro-caudal levels of the VMNvl of rats in all stages of the estrous cycle in a way that co-expression is increased in neurons at all levels of the VMNvl. In fact, co-localization increases in neurons in the rostral levels, where the expression of the receptors is smaller, from estrus to proestrus and in the caudal levels, where it is higher, from metestrus to proestrus. Results have also shown that only half the neurons expressing estradiol-dependent and non-dependent PR express ERa that does not change along VMNvl rostro-caudal levels. Contrariwise, the majority of neurons expressing ERa at proestrus also express $\mathrm{PR}$, and this increase is most evident at caudal levels.

Results on uterine weights and hormone levels in the present study are in agreement with previous ones (Butcher et al. 1974, Smith et al. 1975, Leite et al. 2014, Martins et al. 2015) by showing an increased uterine weight and hormone levels at proestrus with subsequent decline along the phases of the estrous cycle. As the animals were allocated to each estrous cycle phase according to the results of the vaginal cytology done at the day of killing, present hormonal determinations confirm the use of vaginal smear cytology for the recognition of the different phases of the estrous cycle in the Wistar rat.

The estimated total number of VMNvl neurons expressing PR is increased at proestrus, which is in agreement with previous studies on the estrous cycle (McGuinnins et al. 1981, Guerra-Araiza et al. 2003, Blaustein 2009) and also with previous studies that used ovariectomized (OVX) rats injected with estradiol (Etgen et al. 1999, Blaustein 2009, Sá et al. 2010, 2013). In a recent study that used genetic strategies to visualize PR-ir neurons in mice, Yang and coworkers (Yang et al. 2013) reported a higher percentage of PR/ERa co-localization (approximately 90\%) than the present results. The gold standard for co-localization studies is confocal microscopy, because it ensures sensitive detection of labeled cells and accurate focusing on the same confocal plane. In this study an epifluorescent microscope has been used, which may have been a limitation as it

Published by Bioscientifica Ltd. 
could introduce some underestimation in the overlap of ERa and PR signaling. However, the discrepancies between the present and previous studies (Blaustein \& Turcotte 1989, Yang et al. 2013) could also be accounted for by other methodological differences, such as the hormonal milieu of the females studied and the rostrocaudal level of the sections screened, because present data suggest co-localization changes along the estrous cycle and along the rostro-caudal levels of the VMNvl. The fact that the number of VMNvl neurons expressing PR increases on natural or exogenous estradiol surges suggests that progesterone has no effect in the amount of neurons expressing PR. However, when the present data estimated at proestrus were compared with previous results obtained from OVX rats injected with estradiol benzoate using the same method (Sá et al. 2010, 2013), 3500 less PR-ir neurons were estimated. This difference could be accounted for the different circulating estradiol levels at proestrus versus OVX rats injected with estradiol benzoate as the dose-dependent effect of estradiol on PR expression in the VMN is well known (Clark et al. 1982, Etgen et al. 1999, Blaustein 2009). Nevertheless, at metestrus, where a second, smaller, surge of progesterone occurs, there is a higher decrease in the number of PR-ir neurons when compared with proestrus. Taken together, these observations provide additional support to the notion that progesterone-PR binding induces the receptor degradation and downregulation (Funabashi et al. 2000, Qiu \& Lange 2003, González-Flores et al. 2004), which could account for the less exuberant increase in the number of PR-ir VMNvl neurons at proestrus. Present results shown at estrus and metestrus phases support the concept that the downregulation of PRs is an important mechanism in the pathway of estrous termination (Parsons et al. 1981, González-Flores et al. 2004).

In general, it is assumed that estradiol downregulates ERa (Lauber et al. 1990, Etgen et al. 1999, Blaustein 2009). Nonetheless, studies have reported some discrepancies by showing no effect (Chakraborty et al. 2003) or an increase in ERa upon estradiol administration to OVX rats in the VMN (Devidze et al. 2005, Malikov \& Madeira 2012). Present observations at proestrus show an increase in the total number of ERa-ir neurons, which may be due to the increased levels of estradiol and not progesterone. In fact, it was previously shown that progesterone downregulates ER binding in the preoptic-hypothalamic area and VMN (Blaustein \& Brown 1984, Brown \& MacLusky 1994), and previous studies in the medial preoptic nucleus and bed nucleus of the stria terminalis (Leite et al. 2014, Martins et al. 2015) further corroborate this finding. Nevertheless, it was also shown that in VMNvl neurons, progesterone promotes ERa expression (Malikov \& Madeira 2012), which is further supported by present data showing an increase in the total number of ERa-ir neurons at metestrus, when a second surge of progesterone occurs. However, at this phase of the cycle, PR-ir neurons are reduced to $60 \%$, which averts a direct action of progesterone and further corroborates the notion that progesterone is able to activate other pathways, namely membrane mechanisms and electrophysiological responses in some neurotransmitter systems (Petitti \& Etgen 1992, Etgen et al. 1999, Mani \& Oyola 2012), increasing ERa expression.

It was reported that approximately all PR-ir neurons in the VMN region co-express ERa (Blaustein \& Turcotte 1989, Warembourg et al. 1989). On the contrary, present results show that only nearly $50 \%$ of PR-ir VMNvl neurons also express ERa and that 40-60\% of ERa-ir VMNvl neurons co-express PR. Furthermore, no differences were shown along the four stages of the cycle in the percentage of PR-ir neurons co-expressing ERa, suggesting that only half of the neurons expressing estradiol-induced PRs co-express ERa, reinforcing the notion that estradiol-induced PR expression is activated both directly and transsynaptically (Blaustein 2009, Sá et al. 2013). The small co-expression of both receptors further support the concept that the VMNvl neurons that do not express ERa but are involved in the promotion of the female sexual behavior express PR and are directly involved in the regulation of estrous initiation and termination.

Data in this study show that the percentage of ERa-expressing neurons that also express PR increases at proestrus, suggesting that the majority of neurons expressing ERa de novo are also PR-ir. Proestrus is the stage of the estrous cycle when the VMN is activated and prepared to relay all sorts of sensorial information into activated motor responses (Etgen et al. 1999, Guerra-Araiza et al. 2003, Pfaff et al. 2008). These results suggest that the high ERa/PR co-localization may be a downstream effect of neuronal activation that triggers molecular mechanisms necessary for the promotion of the behavioral response. In addition, at metestrus, there is the combination of a high number of ERa-ir neurons with the lowest percentage of ERa/PR co-localization due to the lowest number of PR-ir neurons, suggesting that at this stage of the estrous cycle, the low combination of PR and ERa expression averts sexual responsiveness triggering estrous termination.

Previous studies have shown that VMNvl connections are topographically organized in a way that inputs reach

Published by Bioscientifica Ltd. 
the caudal VMNvl to be integrated and relayed to the rostral VMNvl, where outputs are sent to the midbrain (Sakuma \& Akaishi 1987, Fahrbach et al. 1989, Flanagan-Cato 2000). The present observations show a higher increase in the percentage of ERa/PR co-localization at VMNvl caudal levels at proestrus, suggesting that combined expression of both receptors warrants the responsiveness of these VMNvl neurons allowing them to modulate the extrinsic input into relayed outputs fundamental to the behavioral response.

With this study, we have shown that successive changes in circulating estradiol and progesterone levels along the estrous cycle induce coordinated changes in the expression of PR and ERa and in the percentage of their co-localization. This variant co-localization of PR and ERa could be an important mechanism in the regulation of received information by the $\mathrm{VMNvl}$ that is relayed to the midbrain. In this way, the female sexual behavior may be methodically modulated by ovarian hormones in $\mathrm{VMNvl}$ neurons through intrinsic and extrinsic mechanisms, triggering the induction and estrous termination.

\section{Declaration of interest}

The authors declare that there is no conflict of interest that could be perceived as prejudicing the impartiality of the research reported.

\section{Funding}

This work was supported by National Funds through FCT - Fundação para a Ciência e a Tecnologia within the scope of the Strategic Project Centro de Morfologia Experimental (CME/FM/UP) - 2012-2013 and Project PEstOE/SAU/UI0121/2011 and by ERDF through the operation POCI-01-0145FEDER-007746 funded by the Programa Operacional Competitividade e Internacionalização - COMPETE2020 and by National Funds through FCT - Fundação para a Ciência e a Tecnologia within CINTESIS, R\&D Unit (UID/ IC/4255/2013)

\section{Author contribution statement}

S I S designed the research. S I S and B M F performed the techniques. All authors were involved in drafting and all approved the manuscript.

\section{Acknowledgements}

The authors wish to thank Prof. M D Madeira for helpful comments on the manuscript.

\section{References}

Blaustein JD 2009 Feminine reproductive behavior and physiology in rodents: integration of hormonal, behavioral and environmental influences. In Hormones, Brain and Behavior, edn 2, pp 67-107. Eds DW Pfaff, AP Arnold, AM Etgen, SE Fahrbach \& RT Rubin. San Diego, CA, USA: Elsevier.
Blaustein JD \& Brown TJ 1984 Progesterone decreases the concentration of hypothalamic and anterior pituitary estrogen receptors in ovariectomized rats. Brain Research 304 225-236. (doi:10.1016/00068993(84)90325-1)

Blaustein JD \& Turcotte JC 1989 Estradiol-induced progestin receptor immunoreactivity is found only in estrogen receptor-immunoreactive cells in guinea pig brain. Neuroendocrinology 49 454-461. (doi:10.1159/000125152)

Blaustein JD \& Gréco B 2002 A progestin antagonist blocks vaginocervical stimulation-induced Fos expression in neurons containing progestin receptors in the rostral medial preoptic area. Journal of Neuroendocrinology 14 109-115. (doi:10.1046/j.00071331.2001.00743.x)

Brown TJ \& MacLusky NJ 1994 Progesterone modulation of estrogen receptors in microdissected regions of the rat hypothalamus. Molecular and Cellular Neuroscience 5 283-290. (doi:10.1006/ mone.1994.1033)

Butcher RL, Collins WE \& Fugo NW 1974 Plasma concentration of LH, FSH, prolactin, progesterone and estradiol-17beta throughout the 4-day estrous cycle of the rat. Endocrinology 94 1704-1708. (doi:10.1210/endo-94-6-1704)

Calizo LH \& Flanagan-Cato LM 2002 Estrogen-induced dendritic spine elimination on female rat ventromedial hypothalamic neurons that project to the periaqueductal gray. Journal of Comparative Neurology 447 234-248. (doi:10.1002/cne.10223)

Calizo LH \& Flanagan-Cato LM 2003 Hormonal-neural integration in the female rat ventromedial hypothalamus: triple labeling for estrogen receptor-alpha, retrograde tract tracing from the periaqueductal gray, and mating-induced Fos expression. Endocrinology 144 5430-5440. (doi:10.1210/en.2003-0331)

Chakraborty TR, Hof PR, Ng L \& Gore AC 2003 Stereological analysis of estrogen receptor alpha $(\mathrm{ER} \alpha)$ expression in rat hypothalamus and its regulation by aging and estrogen. Journal of Comparative Neurology 466 409-421. (doi:10.1002/cne.10906)

Clark CR, MacLusky NJ \& Naftolin F 1982 Oestrogen induction of progestin receptors in the rat brain and pituitary gland: quantitative and kinetic aspects. Journal of Endocrinology 93 339-353. (doi:10.1677/ joe.0.0930339)

Devidze N, Mong JA, Jasnow AM, Kow LM \& Pfaff DW 2005 Sex and estrogenic effects on coexpression of mRNAs in single ventromedial hypothalamic neurons. PNAS 102 14446-14451. (doi:10.1073/ pnas.0507144102)

Etgen AM, Chu HP, Fiber JM, Karkanias GB \& Morales JM 1999 Hormonal integration of neurochemical and sensory signals governing female reproductive behavior. Behavioral Brain Research 105 93-103. (doi:10.1016/S0166-4328(99)00085-6)

Fahrbach SE, Morrell JI \& Pfaff DW 1989 Studies of ventromedial hypothalamic afferents in the rat using three methods of HRP application. Experimental Brain Research 77 221-233. (doi:10.1007/ BF00274980)

Fernández-Guasti A, Kruijver FP, Fodor M \& Swaab DF 2000 Sex differences in the distribution of androgen receptors in the human hypothalamus. Journal of Comparative Neurology 425 422-435. (doi:10.1002/1096-9861(20000925)425:3<422::aidcne7>3.0.CO;2-H)

Fitzpatrick SL, Berrodin TJ, Jenkins SF, Sindoni DM, Deecher DC \& Frail DE 1999 Effect of estrogen agonists and antagonists on induction of progesterone receptor in a rat hypothalamic cell line. Endocrinology 140 3928-3937. (doi:10.1210/endo.140.9.7006)

Flanagan-Cato LM 2000 Estrogen-induced remodeling of hypothalamic neural circuitry. Frontiers in Neuroendocrinology 21 309-329. (doi:10.1006/frne.2000.0204)

Funabashi T, Kleopoulos SP, Brooks PJ, Kimura F, Pfaff DW, Shinohara K $\&$ Mobbs CV 2000 Changes in estrogenic regulation of estrogen receptor a mRNA and progesterone receptor mRNA in the female http://joe.endocrinology-journals.org

DOI: $10.1530 / J O E-16-0663$
๑) 2017 Society for Endocrinology Printed in Great Britain
Published by Bioscientifica Ltd. 
rat hypothalamus during aging: an in situ hybridization study. Neuroscience Research 38 85-92. (doi:10.1016/S0168-0102(00)00150-4)

Garcia-Falgueras A, Ligtenberg L, Kruijver FP \& Swaab DF 2011 Galanin neurons in the intermediate nucleus (InM) of the human hypothalamus in relation to sex, age, and gender identity. Journal of Comparative Neurology 519 3061-3084. (doi:10.1002/cne.22666)

González-Flores O, Guerra-Araiza C, Cerbón M, Camacho-Arroyo I \& Etgen AM 2004 The $26 \mathrm{~S}$ proteasome participates in the sequential inhibition of estrous behavior induced by progesterone in rats. Endocrinology 145 2328-2336. (doi:10.1210/en.2003-1162)

Guerra-Araiza C, Villamar-Cruz O, González-Arenas A, Chavira R \& Camacho-Arroyo I 2003 Changes in progesterone receptor isoforms content in the rat brain during the estrous cycle and after oestradiol and progesterone treatments. Journal of Neuroendocrinology $\mathbf{1 5}$ 984-990. (doi:10.1046/j.1365-2826.2003.01088.x)

Gundersen HJG, Jensen EBV, Kiêu K \& Nielsen J 1999 The efficiency of systematic sampling in stereology - reconsidered. Journal of Microscopy 193 199-211. (doi:10.1046/j.1365-2818.1999.00457.x)

Kruijver FP, Balesar R, Espila AM, Unmehopa UA \& Swaab DF 2002 Estrogen receptor-alpha distribution in the human hypothalamus in relation to sex and endocrine status. Journal of Comparative Neurology 454 115-139. (doi:10.1002/cne.10416)

Kudwa AE \& Rissman EF 2003 Double oestrogen receptor $\alpha$ and $\beta$ knockout mice reveal differences in neural oestrogen-mediated progestin receptor induction and female sexual behaviour. Journal of Neuroendocrinology 15 978-983. (doi:10.1046/j.13652826.2003.01089.x)

Lauber AH, Romano GJ, Mobbs CV \& Pfaff DW 1990 Estradiol regulation of estrogen receptor messenger ribonucleic acid in rat mediobasal hypothalamus: an in situ hybridization study. Journal of Neuroendocrinology 2 605-611. (doi:10.1111/j.1365-2826.1990. tb00454.x)

Lee KL, Dai Q, Hansen EL, Saner CN \& Price TM 2010 Modulation of ATP-induced calcium signaling by progesterone in T47D-Y breast cancer cells. Molecular and Cellular Endocrinology 319 109-115. (doi:10.1016/j.mce.2010.01.004)

Leite C, Madeira MD \& Sá SI 2014 Effects of sex steroids and estrogen receptor agonists on the expression of estrogen receptor alpha in the principal division of the bed nucleus of the stria terminalis of female rats. Brain Research 1582 99-106. (doi:10.1016/j. brainres.2014.07.041)

Liu X \& Shi H 2015 Regulation of estrogen receptor $\alpha$ expression in the hypothalamus by sex steroids: implication in the regulation of energy homeostasis. International Journal of Endocrinology 2015949085. (doi:10.1155/2015/949085)

Madeira MD, Andrade JP, Lieberman AR, Sousa N, Almeida OFX \& Paula-Barbosa MM 1997 Chronic alcohol consumption and withdrawal do not induce cell death in the suprachiasmatic nucleus, but lead to irreversible depression of peptide immunoreactivity and mRNA levels. Journal of Neuroscience 17 1302-1319.

Malikov V \& Madeira MD 2012 Regulation of ERa protein expression by $17 \mathrm{~b}$-estradiol in cultured neurons of hypothalamic ventromedial nucleus. Neurochemical Research 38 82-89. (doi:10.1007/s11064-0120891-1)

Mani SK \& Oyola MG 2012 Progesterone signaling mechanisms in brain and behavior. Frontiers in Endocrinology 3 7. (doi:10.3389/ fendo.2012.00007)

Martins SI, Madeira MD \& Sá SI 2015 Effects of gonadal steroids and of estrogen receptor agonists on the expression of estrogen receptor alpha in the medial preoptic nucleus of female rats. Neuroscience $\mathbf{3 1 0}$ 63-72. (doi:10.1016/j.neuroscience.2015.09.030)

McGinnis MY, Parsons B, Rainbow TC, Krey LC \& McEwen BS 1981 Temporal relationship between cell nuclear progestin receptor levels and sexual receptivity following intravenous progesterone administration. Brain Research 218 365-371. (doi:10.1016/00068993(81)91315-9)
Micevych P, Soma KK \& Sinchak K 2008 Neuroprogesterone: key to estrogen positive feedback? Brain Research Reviews $\mathbf{5 7}$ 470-480. (doi:10.1016/j.brainresrev.2007.06.009)

Moffat CA, Rissman EF, Shupnik MA \& Blaustein JD 1998 Induction of progestin receptors by estradiol in the forebrain of estrogen receptor- $\alpha$ gene-disrupted mice. Journal of Neuroscience 18 9556-9563.

Normandin JJ \& Murphy AZ 2008 Nucleus paragigantocellularis afferents in male and female rats: organization, gonadal steroid receptor expression, and activation during sexual behavior. Journal of Comparative Neurology 508 771-794. (doi:10.1002/cne.21704)

Omoto Y, Imamov O, Warner M \& Gustafsson JA 2005 Estrogen receptor alpha and imprinting of the neonatal mouse ventral prostate by estrogen. PNAS 102 1484-1489. (doi:10.1073/pnas.0409168102)

Parsons B, McGinnis MY \& McEwen BS 1981 Sequential inhibition of progesterone: effects on sexual receptivity and associated changes in brain cytosol progestin binding in the female rat. Brain Research 221 149-160. (doi:10.1016/0006-8993(81)91069-6)

Paxinos G \& Watson C 1998 The Rat Brain Stereotaxic Coordinates, edn 4. San Diego, CA, USA: Academic Press.

Petitti N \& Etgen AM 1992 Progesterone promotes rapid desensitization of alpha1-adrenergic receptor augmentation of cAMP formation in rat hypothalamic slices. Neuroendocrinology 55 1-8. (doi:10.1159/000126089)

Pfaff D, Ribeiro A, Matthews J \& Kow LM 2008 Concepts and mechanisms of generalized central nervous system arousal. Annals of the New York Academy of Sciences 1129 11-25. (doi:10.1196/ annals.1417.019)

Qiu M \& Lange CA 2003 MAP kinases couple multiple functions of human progesterone receptors: degradation, transcriptional synergy, and nuclear association. Journal of Steroid Biochemistry and Molecular Biology 85 147-157. (doi:10.1016/S0960-0760(03)00221-8)

Quesada A, Romeo HE \& Micevych P 2007 Distribution and localization patterns of estrogen receptor-beta and insulin-like growth factor-1 receptors in neurons and glial cells of the female rat substantia nigra: localization of ERbeta and IGF-1R in substantia nigra. Journal of Comparative Neurology 503 198-208. (doi:10.1002/cne.21358)

Rebouças EC, Leal S, Silva SM \& Sá SI 2016 Changes in the female arcuate nucleus morphology and neurochemistry after chronic ethanol consumption and long-term withdrawal. Journal of Chemical Neuroanatomy 77 30-40. (doi:10.1016/j.jchemneu.2016.05.001)

Sá SI, Pereira PA, Paula-Barbosa MM \& Madeira MD 2010 Role of neural afferents as mediators of estrogen effects on the hypothalamic ventromedial nucleus. Brain Research 1366 60-70. (doi:10.1016/j. brainres.2010.10.043)

Sá SI, Pereira PA, Malikov V \& Madeira MD 2013 Role of estrogen receptor $\alpha$ and $\beta$ in the induction of progesterone receptors in hypothalamic ventromedial neurons. Neuroscience 238 159-167. (doi:10.1016/j. neuroscience.2013.02.023)

Sá SI, Pereira PA, Malikov V, Ferreira IM \& Madeira MD 2014 Role of plasma membrane estrogen receptors in mediating the estrogen induction of progesterone receptors in hypothalamic ventromedial neurons. Journal of Comparative Neurology 522 298-307. (doi:10.1002/ cne.23396)

Sá SI, Fonseca BM, Teixeira N \& Madeira MD 2015 Estrogen receptors $\alpha$ and $\beta$ have different roles in the induction and trafficking of progesterone receptors in hypothalamic ventromedial neurons. FEBS Journal 282 1126-1136. (doi:10.1111/febs.13207)

Sakuma Y \& Akaishi T 1987 Cell size, projection path, and localization of estrogen-sensitive neurons in the rat ventromedial hypothalamus. Journal of Neurophysiology $\mathbf{5 7} 1148-1159$.

Samalecos A \& Gellersen B 2008 Systematic expression analysis and antibody screening do not support the existence of naturally occurring progesterone receptor (PR)-C, PR-M, or other truncated PR isoforms. Endocrinology 149 5872-5887. (doi:10.1210/en.2008-0602)

Shughrue PJ, Bushnell CD \& Dorsa DM 1992 Estrogen receptor messenger ribonucleic acid in female rat brain during the estrous

Published by Bioscientifica Ltd. 
cycle: a comparison with ovariectomized females and intact males. Endocrinology 131 381-388. (doi:10.1210/en.131.1.381)

Smith MS, Freeman ME \& Neill JD 1975 The control of progesterone secretion during the estrous cycle and early pseudopregnancy in the rat: prolactin, gonadotropin and steroid levels associated with rescue of the corpus luteum of pseudopregnancy. Endocrinology 96 219-226. (doi:10.1210/endo-96-1-219)

Snoeren EM, Antonio-Cabrera E, Spiteri T, Musatov S, Ogawa S, Pfaff DW \& Ågmo A 2015 Role of oestrogen $\alpha$ receptors in sociosexual behaviour in female rats housed in a seminatural environment. Journal of Neuroendocrinology 27 803-818. (doi:10.1111/jne.12321)

Tetel MJ, Siegal NK \& Murphy SD 2007 Cells in behaviourally relevant brain regions coexpress nuclear receptor coactivators and ovarian steroid receptors. Journal of Endocrinology 19 262-271. (doi:10.1111/ j.1365-2826.2007.01526.x)

Warembourg M, Jolivet A \& Milgrom E 1989 Immunohistochemical evidence of the presence of estrogen and progesterone receptors in the same neurons of the guinea pig hypothalamus and preoptic area. Brain Research 480 1-15. (doi:10.1016/0006-8993(89)91561-8)

West MJ, Slomianka L \& Gundersen HJG 1991 Unbiased stereological estimation of the total number of neurons in the subdivisions of the rat hippocampus using the optical fractionator. Anatomical Record 231 482-497. (doi:10.1002/ar.1092310411)

Yang CF, Chiang MC, Gray DC, Prabhakaran M, Alvarado M, Juntti SA, Unger EK, Wells JA \& Shah NM 2013 Sexually dimorphic neurons in the ventromedial hypothalamus govern mating in both sexes and aggression in males. Cell 153 896-909. (doi:10.1016/j.cell.2013.04.017)

Received in final form 1 March 2017

Accepted 10 March 2017

Accepted Preprint published online 10 March 2017
๑) 2017 Society for Endocrinology Printed in Great Britain
Published by Bioscientifica Ltd 